\title{
Detection of Delamination Damages in Thin Composite Plates using Noncontact Measurement of Structural Dynamic Behavior
}

\author{
By Christian Pongratz* \\ Matthias Schlamp \\ Bastian Jungbauer ${ }^{+}$ \\ Ingo Ehrlich ${ }^{+}$
}

\begin{abstract}
Plate-shaped composite structures are typically implemented in a variety of applications related to the aeronautics or automotive industry. Subjected to real environmental conditions, those structures may be burdened by impact loads. Low-velocity impacts in particular are a high safety issue since they can cause barely visible or invisible damages inside the structure. The caused defects vary from notches and cracks to delaminations underneath the surface. Their common consequence is a significant reduction of compression and fatigue strength. To determine the integrity of composite structures, different principles, mainly ultrasonic testing, can be used. Because these methods are typically time consuming, a faster and more easily applied integral test method might offer advantages. Such a test method can be gained by analyzing the vibrational behavior of composite structures. Using the vibrational analysis approach, not only the response frequencies are considered, but also other modal properties, especially the modal damping. The single measurement of the response frequencies might prove an insufficient damage indication because their frequency shift is subtle and is strongly dependent on its present bearing. For the experimental tests, plate-shaped specimens were chosen due to the simple geometry and relevance to applications. By using structural dynamic measurements and analysis, intact as well as impact damaged plates were measured. For the contact-less measurements of the vibrating specimens, a Laser Scanning Vibrometer is used. The plate-shaped specimens are oscillated by acoustic excitation. The necessary bearing is realized in the form of a thread suspension or, more generalized, a free boundary condition. This minimizes any hampering of the evolving modes of vibration. The obtained results of the conducted measurements are compared and discussed.
\end{abstract}

Keywords: Carbon fiber-reinforced plastics, Composites, Modal properties, Structural dynamic analysis and measurement, thin plates.

\footnotetext{
* Master Student, Ostbayerische Technische Hochschule (OTH) Regensburg, Germany.

${ }^{\star}$ PhD Student, Ostbayerische Technische Hochschule (OTH) Regensburg, Germany.

${ }^{+}$Laboratory Engineer, Ostbayerische Technische Hochschule (OTH) Regensburg, Germany.

${ }^{\dagger}$ Professor, Ostbayerische Technische Hochschule (OTH) Regensburg, Germany.
} 


\section{Introduction}

The application of fiber-reinforced plastics can be considered state-of-the-art in the fields of aeronautics as well as in the automotive industry. Generally, fiberreinforced plastics are advantageous due to their comparatively low density paired with superior specific stiffness and strength. Therefore, such materials are a reasonable choice, wherever high performance or weight reduction is crucial (Schürmann, 2007).

However, fiber-reinforced plastics also exhibit adverse characteristics. One of the primary obstacles is their vulnerability to delamination damages (Ehrlich, 2004; Ehrlich et al., 2015; Schoßig, 2011). These damages are mostly caused by low-velocity impacts and impair the compression and fatigue strength considerably. An aspect often found in components with certain impact damages is the virtual invisibility of the damage from the outside. Consequently, these impact damages represent a particular safety issue and are referred to as barely visible impact damage (BVID) (Morlo and Kunz, 1990). As it is problematic to significantly strengthen fiber-reinforced plastics against impact damages, structural health monitoring (SHM) systems for composites are a current research topic. These SHM systems enable an early damage detection and regular information concerning the current material status. Hence, the central concept of these systems is to enable structure integrity statements by cyclic or permanent monitoring of the composite component.

During their usage in real applications, components are usually subjected to different operation loads, resulting not only in potential distortions, but also leading to oscillations of the component. Hence, it is reasonable to base possible structure integrity statements on the oscillatory or vibrational behavior. To characterize the vibrational behavior of a component, a modal or structural dynamic analysis is typically applied. The fundamentals and current state of this measuring method is, for instance, described by Ewins (2000a). Apart from isotropic materials, modal testing is just as feasible for composites, described for example in Gibson (2000), and investigations on their vibrational behavior are currently still ongoing. The aim is to achieve a classification method by evaluating and comparing the structural dynamic behavior of damaged and intact fiberreinforced plastic specimens by utilizing similar measurement approaches. A structural dynamic analysis enables the determination of the corresponding modal or structural dynamic properties. These parameters form the basis of a possible damage indication and are therefore thoroughly investigated.

Structural dynamic properties are composed of eigenfrequencies, eigenmodes and the damping behavior described via the damping ratio (Dresig and Holzweißig, 2010). Additionally, the calculation method for the storage and the loss modulus are presented, which describe the viscoelastic properties of composites and plastics. Although, initial tests have shown that surveying eigenfrequencies is less relevant for establishing a composite SHM system as the shift of response frequencies is often insufficiently conclusive. For the principle structural dynamic tests, three topics must be clearly defined. These are the measurement and excitation method as well as the bearing type. Based on this, it 
is possible to decide upon the most sensible measurement setup for a particular component.

\section{Materials and Methods}

In the following, the plate-shaped specimens' manufacturing, the creation of artificial defects and quality control methods that are discussed. Moreover, the current measurement setup and the calculation approach for determining the structural dynamic properties are described.

\section{Specimen Manufacturing}

The specimens were manufactured by stacking layers of pre-impregnated fibers, so-called prepregs, followed by a curing process in the autoclave. Compared to other manufacturing processes, this ensures high quality specimens and good reproducibility (Schürmann, 2007). The selected prepreg materials consist of carbon fibers and an epoxy matrix. The laminate stacking sequences of the unidirectional (UD) prepregs are listed in Table 1, while the corresponding coordinate systems are presented in Figure 1. The fiber angle $\alpha$ is defined positive in counterclockwise direction. For a laminate layer with $0^{\circ}$-orientation, the $\mathrm{x}-, \mathrm{y}-$, $\mathrm{z}$-axis are equal to the 1-, 2-, 3-direction of the UD layer.

Table 1. Stacking Sequence of the Specimen Plates

\begin{tabular}{ccc}
\hline Series Name & Number of Layers & Stacking Sequence \\
\hline 401 & 8 UD layers & {$[0]_{8}$} \\
402 & 8 UD layers & {$\left[[0 / 90]_{2}\right]_{\mathrm{s}}$} \\
403 & 8 UD layers & {$\left[[0 / 90]_{2}\right]_{\mathrm{s}}$} \\
404 & 8 UD layers & {$\left[[0 / 90]_{2}\right]_{\mathrm{s}}$} \\
405 & 8 UD layers & {$\left[[0 / 90]_{2}\right]_{\mathrm{s}}$} \\
406 & 16 UD layers & {$\left[[0 / 90]_{4}\right]_{\mathrm{s}}$} \\
407 & 8 UD layers & {$\left[[-45 /+45]_{2}\right]_{\mathrm{s}}$} \\
408 & 8 UD layers & {$[-45 / 0 /+45 / 90]_{\mathrm{s}}$} \\
409 & 8 UD layers & {$[0]_{8}$} \\
\hline
\end{tabular}

Figure 1. Plate Coordinate System (CS) in Global and Local Scope

(a) Plate in Global CS

$$
\mathrm{z} \text {-axis }
$$

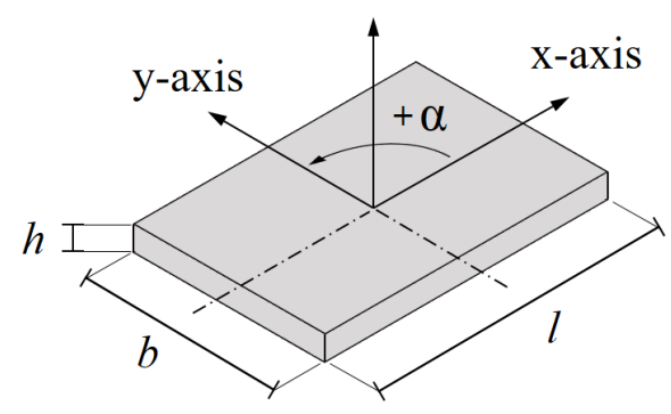

(b) $30^{\circ}-U D$ in Local CS

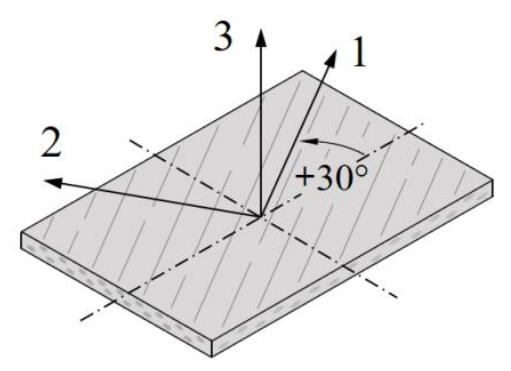


The curing process, specifically the autoclave cycle, was programmed in accordance to the manufacturer's recommendations. The cured specimens were water-jet cut to match the geometrical dimensions of $150 \mathrm{~mm} \times 100 \mathrm{~mm}$, defined in DIN 65561 (1991). The plate thickness is about $1.7 \mathrm{~mm} \pm 0.1 \mathrm{~mm}$ for 8 layers and $3.4 \mathrm{~mm} \pm 0.1 \mathrm{~mm}$ for 16 layers. For every series a total of six plates was manufactured.

\section{Fiber Volume Content}

To ensure that the plate-shaped specimen suffice the expected quality, the fiber volume content was examined. The experimental analysis to determine the fiber volume content is defined in procedure B of DIN EN ISO 1172 (1998). However, this determination method is extensive and results in a decrease in specimens. In contract to this destructive testing method, it is possible to calculate the fiber volume content $\varphi_{\mathrm{f}}$ using

$$
\varphi_{\mathrm{f}}=\frac{n \cdot m_{\mathrm{A}, \mathrm{f}}}{h \cdot \rho_{\mathrm{f}}},
$$

by assuming that only the matrix resin flows off during the curing process. The fiber weight per unit area $m_{\mathrm{A}, \mathrm{f}}$ and the fiber density $\rho_{\mathrm{f}}$ is currently obtained from the supplied material data sheet of the prepreg system. The number of layers $n$ is passed on from the laying process while the specimens' height $h$ can be measured. For validation, the calculated and the experimentally identified fiber volume content were compared using test specimens and showed a good correlation. The calculated fiber volume content over all plates and series amounts from 61 vol. $\%$ to 64 vol.\% and can be considered close to ideal (Schürmann, 2007). The deviation within a specimen series is small with less than 1 vol.\%. To appropriately use this calculation method, the previously mentioned test needs to be performed beforehand.

\section{Ultrasonic Testing}

Additionally, to the fiber volume content measurements, ultrasonic testing was applied as a quality control test, since it allows for the examination of the plate's material integrity. Hence, following the manufacturing process, each plate was checked for manufacturing defects and other previously obtained damages with the help of a Hillger ultrasonic measuring instrument. Moreover, the artificially damaged plates were examined using ultrasonic testing in order to depict delamination areas.

Figure 2 shows the panel adjustments and an exemplary C-scan image of the auxiliary reflector signal for Plate 407-003. In accordance to Table 1, this specimen is the third manufactured plate of Series 407 with a $\pm 45^{\circ}$ stacking sequence. The adjusted panels displayed in Figure 2(a) are, in ascending order, the surface signal panel [1], the rear signal panel [2] and the auxiliary reflector panel [3]. The measurements were performed using a $5 \mathrm{MHz}$ probe in pulse-echo mode. In the lower left of the plate's C-scan image, a punch hole reinforcement ring is visible. The reinforcement ring is affixed to the plates for adjustments and as a 
reference. The plate's form is non-rectangular due to a removal gap in the specimen mounting. Otherwise, the C-scan of Plate 407-003 shows no discontinuities and the plate can be deemed undamaged.

Figure 2. Ultrasonic Testing of Specimen Plates

(a) Panel Adjustment

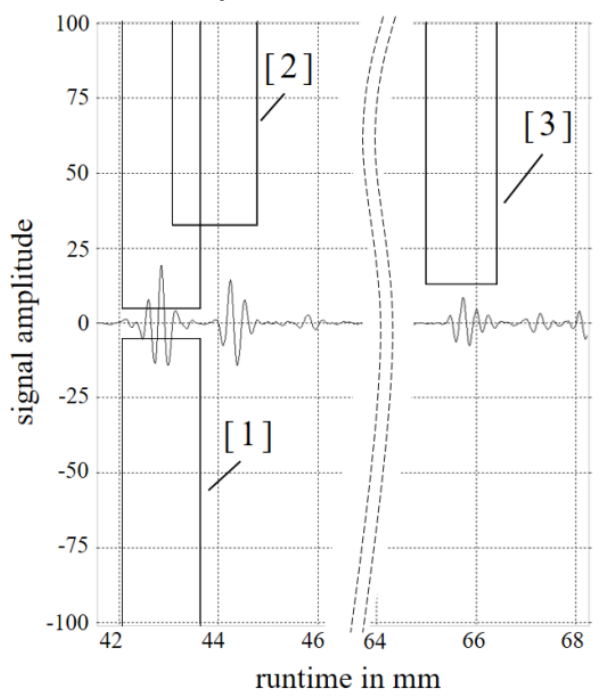

(b) $C$-scan Image

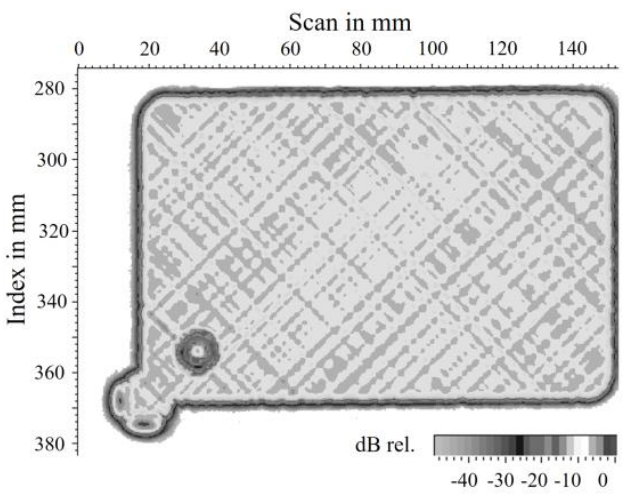

\section{Artificial Impacting}

An impact pendulum was used to create a defined and reproducible lowvelocity impact damage, thus enabling the comparison of intact and damaged plates. The main parts of the impact pendulum, shown in Figure 4, are the $3.2 \mathrm{~kg}$ hammer with a spherical steel impactor of $16 \mathrm{~mm}$ diameter and the support with impactor openings on both sides. Specimens chosen for damage analysis were rigidly clamped at the corners and hit perpendicular to the plate plane at the center. The initial energy of the impact pendulum was set to $5.5 \mathrm{~J}$ for the laminates with 8 layers, as $3.3 \mathrm{~J}$ per millimeter thickness is recommended by DIN 65561 (1991). The corresponding impact velocity for $5.5 \mathrm{~J}$ is approximately $1.9 \mathrm{~m} / \mathrm{s}$. 
Figure 3. Schematic Side View of the Impact Pendulum

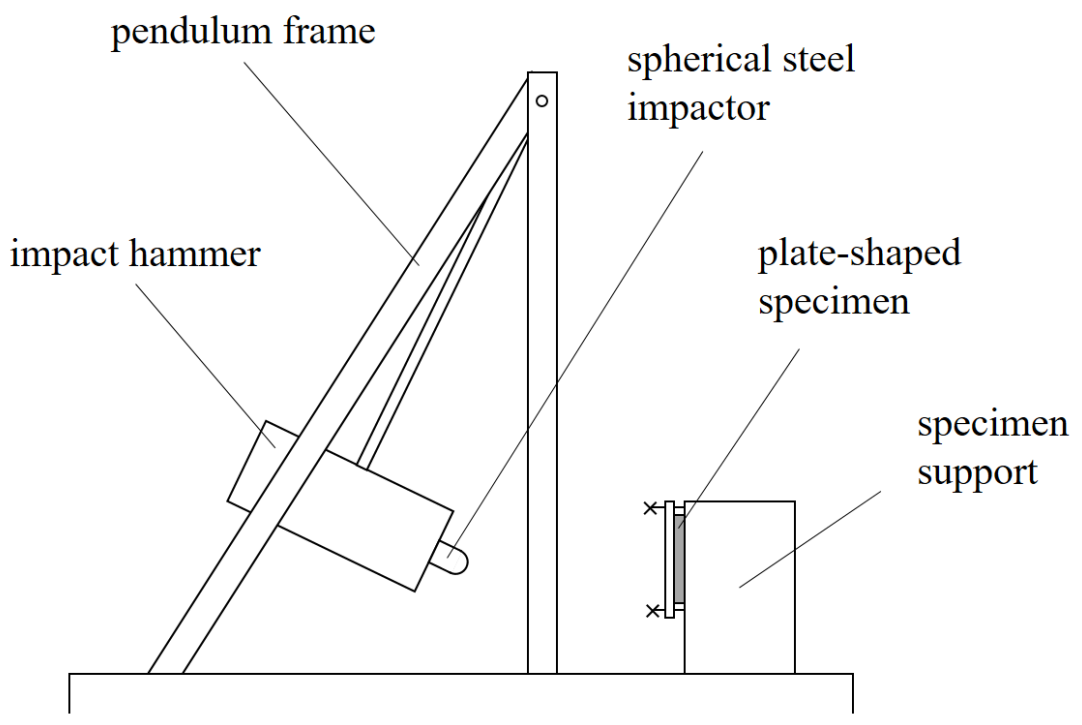

\section{Measurement Setup}

In order to characterize and survey vibrations, specimens are forced to artificially develop oscillations by excitation followed by a measurement of the area with high amplitudes. To perform such measurements in a laboratory scale, the customized measurement setup portrayed in Figure 4 was developed and optimized.

Figure 4. Schematic of the Experimental Setup and Cabling

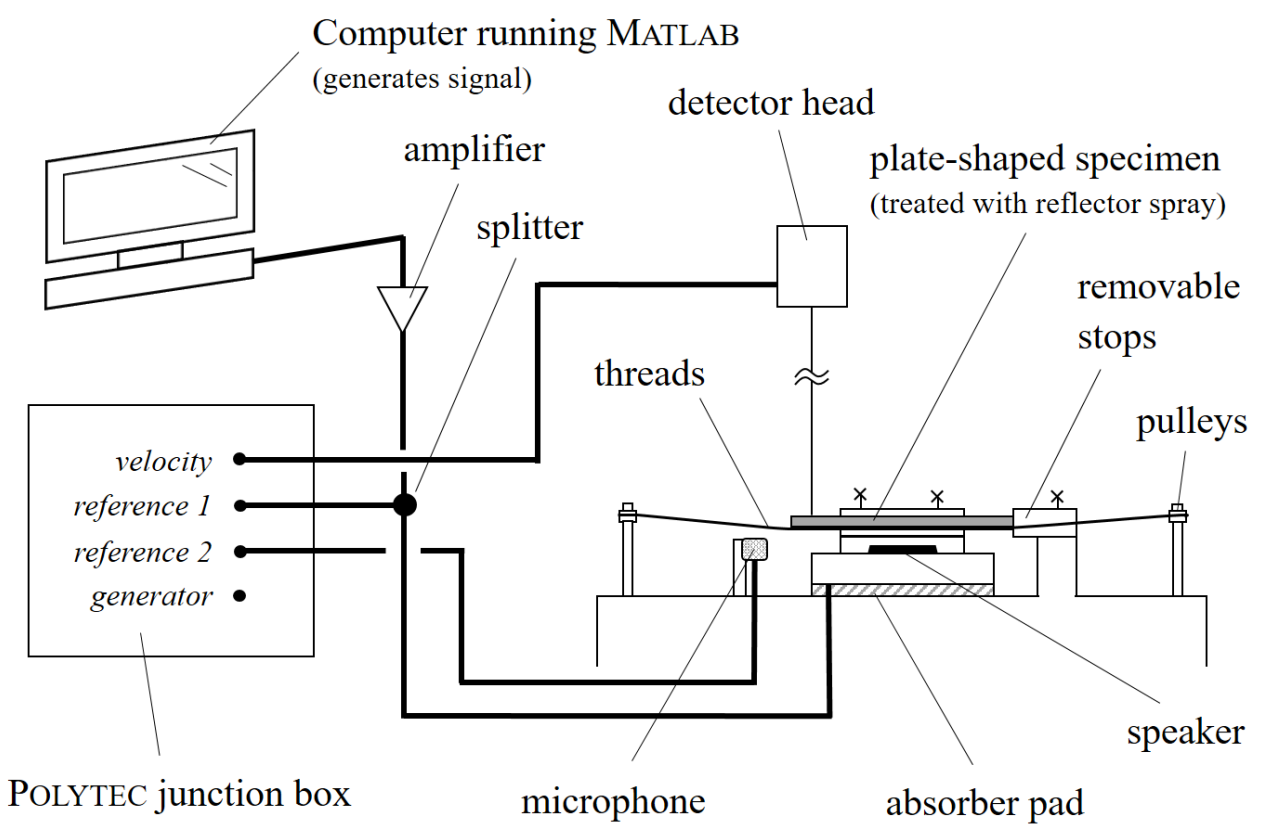


The essential part of the measurement setup is a type PSV 400 Polytec Laser Scanning Vibrometer. A Laser Scanning Vibrometer facilitates highly sensitive and contact-free velocity measurements based on the Doppler Effect. Defined measurement points need to be optically accessible and can be surveyed in succession.

In order to cause the specimen plates to vibrate, acoustic excitation is provided by a speaker placed underneath the plate as shown in Figure 4. Following the speaker's specifics, excitation between $10 \mathrm{~Hz}$ to $20.000 \mathrm{~Hz}$ is possible with a maximum sound pressure of $95 \mathrm{~dB}$ close to the driver unit. Speaker excitation enables a wide variety of test signals, for example the usage of periodic mono-frequent signals or transient frequency sine sweeps. Acoustic excitation is limited by the comparatively low maximum excitation strength and the impossibility to excite antisymmetric nodes proficiently. The latter was analytically verified by $\mathrm{Wu}$ and Mosley (1995).

The bearing of the plate is realized as a suspended type with free-free boundary conditions. Here the edges of the tested specimen are not clamped. For this, a single $0.2 \mathrm{~mm}$ thick nylon thread is crossed over and turned by pulleys at the four corners. A hanging mass at one end of the thread guarantees consistent thread tension. Bearings with free boundaries are sufficient as they do not restrict any arising mode shapes and supposedly have little influence on the damping behavior. However, such bearings permit rigid body movements of the specimen plate, and therefore a high-pass filter is required.

\section{Structural Dynamic Properties}

An experimental modal analysis yields the three modal or structural dynamic properties. As shown in Figure 5, each eigenmode possesses its own eigenfrequency and damping ratio. The eigenfrequencies and damping ratios in Figure 5 are displayed in the time domain, in this case velocity over time. To evaluate several superimposing eigenfrequencies and their associated damping ratios, the time signals are transferred into the frequency domain using a Fast Fourier Transformation (FFT) algorithm. The main idea of any Fourier Transformation is to identify and order periodic parts in an output signal (Ewins, 2000b).

The signal sampling of the Laser Scanning Vibrometer was set considerably higher than required by the Nyquist-Shannon sampling theorem, to not only avoid aliasing but to gain high-quality signals (Co. Polytec, 2013). Furthermore, the output signal was altered to approach zero at the start and end of the measurement to avoid a cutting-off effect, which is otherwise common for the applied rectangular signal window (Ewins, 2000b). This was done by customizing the Matlab signal generator. Applying other signal windows to correct the measured signal could also be viewed as a legitimate alternative. However, preliminary tests indicated that calculations based on such a modified measurement signal would yield other, likely distorted structural dynamic property values. 
Figure 5. Structural Dynamic Properties in the Time Domain

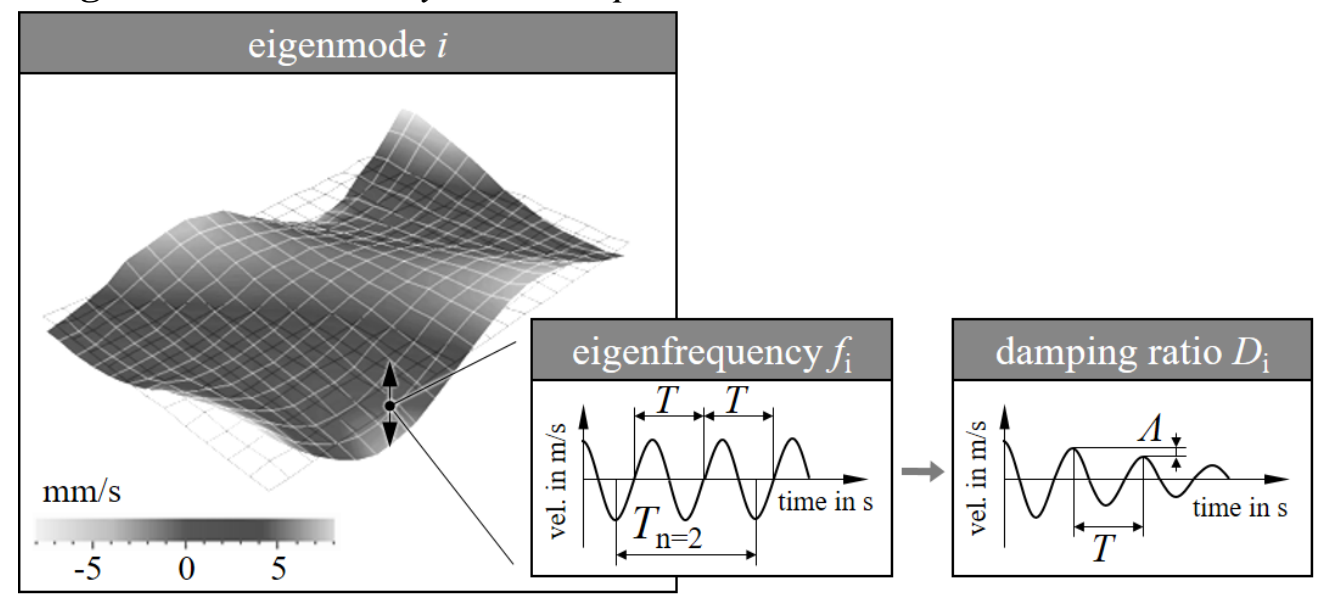

\section{Eigenmode}

The eigenmodes, or shortened modes, are experimentally measured by surveying a grid of measurement points in succession while maintaining harmonic excitation at the chosen eigenfrequency. The determination of the eigenfrequencies is described in Subsection "Eigenfrequency". The Polytec software of the Laser Scanning Vibrometer then proceeds to rectify the signal phases and composes a three-dimensional animation clip as shown before in Figure 5. To correctly label or number the measured mode shapes and to get a closer insight on the vibrational behavior of composites besides, a simulation using the Finite Element Method was performed. The simulation was conducted with Ansys Workbench and the composite tool ACP. As the data sheet did not specify all necessary characteristic values of the material, an analytical approach with overlapping classic laminate theory beams was used. Based on this method, good estimations for additional characteristic values were gained, by linking stiffness expressions with measurable eigenfrequencies (Ehrlich, 2004; Gross et al., 2011; Schürmann, 2007).

\section{Eigenfrequency}

To measure the eigenfrequencies, the plate-shaped specimens are excited using a customized slow frequency sine sweep. The eigenfrequencies and also the damping ratios were measured at eleven measurement points, each for a total of five times. As shown in Figure 6(a), the measurement points are scattered deliberately across one fourth of the plate's surface as symmetrical vibrational behavior was assumed. In the obtained frequency spectrum, the damped eigenfrequencies are indicated by velocity resonance peaks and could simply be picked at the highest point. 


\section{Damping Ratio}

The damping ratio calculations are based on the same frequency spectrum and measurement points as used for the eigenfrequency determination. The modal damping ratio $D_{\mathrm{i}}$ is calculated by applying the peak width at a half-height method to a resonance peak (Dresig and Holzweißig, 2010). This method allows the evaluation of several resonance peaks in one frequency spectrum and thus enables the calculation of the damping ratio for multiple eigenmodes. In accordance to Figure 6(b), the damping ratio $D_{\mathrm{i}}$ can be calculated for a certain eigenmode $i$ by

$$
D_{\mathrm{i}}=\frac{f_{2}-f_{1}}{2 f_{0}} \text { or } D_{\mathrm{i}}=\frac{\Delta f_{1}}{2 f_{0}} \text {. }
$$

The measured damping ratio mainly represents the material damping but includes some amount of parasitic damping as well. Parasitic damping is composed of energy dissipation in the surrounding air, the bearing or fixations as well as in the form of sound waves or damping mechanism in joints and could only be minimized as well as possible (Gibson, 2012). As a result, the measured damping ratios inherently exceed the actual material damping.

Figure 6. Determination Method for the Structural Dynamic Properties

(a) Measurement Points

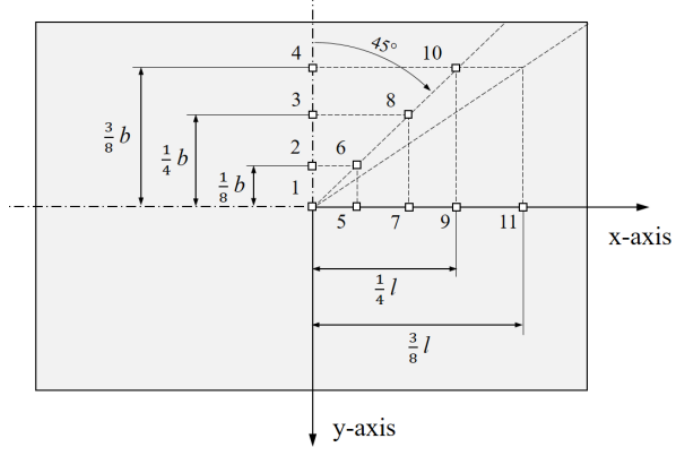

(b) Damping Ratio Calculation

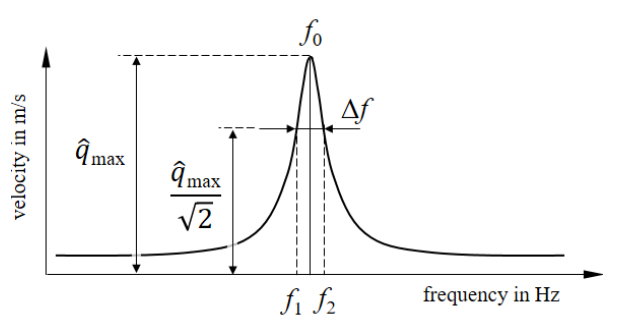

Dynamic Modulus

Additionally, the calculation method to determine the storage and loss modulus of pure flexural modes is derived in the following. These two moduli are used to describe viscoelasticity, the property to respond to stresses with a combination of elastic, viscous and plastic strain, exhibited by fiber-reinforced plastics and plastics in general (DIN EN ISO 6721-1, 2011). The moduli were determined following procedure B of DIN EN ISO 6721-3 (1996). For this the geometrical dimensions and the density of the specimens must be on-hand. The storage modulus $E_{\mathrm{f}}^{\prime}$ is calculated by

$$
E_{\mathrm{f}}^{\prime}=\left(4 \pi \cdot \sqrt{3 \rho} \cdot \frac{l^{2}}{h}\right)^{2} \cdot\left(\frac{f_{\mathrm{i}}}{k_{\mathrm{i}}^{2}}\right)^{2},
$$

whereas the loss modulus $E^{\prime \prime}{ }_{\mathrm{f}}$ is calculated by

$$
E_{\mathrm{f}}^{\prime \prime}=E_{\mathrm{f}}^{\prime \prime} \cdot \tan \delta_{\mathrm{f}} \text {. }
$$


As shown by equation (4), the two moduli are linked by damping, due to the fact that $\tan \delta_{\mathrm{f}}=2 D_{\mathrm{i}}$. The $k$-factor calculation is described in DIN EN ISO 6721-3 (1996) or other literature, for instance in Dresig and Holzweißig (2010). This $k$-factor is related to the eigenvalue problem concerning vibrational equations and can be regarded as a fitting factor that alters in dependence of the eigenmode and present bearing type.

\section{Results and Discussion}

In this section, ultrasonic investigations on the damage area dimensions and shapes are presented and discussed. Furthermore, the change in the vibrational behavior due to impact damages is outlined and the corresponding experimental data are graphically displayed. Additionally to the comparison report, the experimental data is used in an attempt to obtain a normalization method for the damping ratio of different fiber-reinforced plates.

\section{Damage Area Evaluation}

As mentioned before, the plate-shaped specimens are surveyed with the ultrasonic measuring instrument to enable the evaluation of the artificially introduced impact damages. As recommended by DIN 65561 (1991), an impact energy of $5.5 \mathrm{~J}$ is a good initial value to achieve a BVID in laminates with 8 layers. The thickness of such laminates is approximately $1.7 \mathrm{~mm}$ and the mentioned impact energy was projected from the $3.3 \mathrm{~J}$ suitable for $1 \mathrm{~mm}$ laminates. In order to realistically estimate if the laminates respond sensitive to impact energy changes, a small test series was conducted around this value. Figure 7(a) portrays the C-scan image of the auxiliary reflector panel for three plates of Series 402. In line with the exceptions, the delamination areas increase with the impact energy. Since a change by $1 \mathrm{~J}$ affects the delamination area rather significantly, it was deemed necessary to determine the damage dimensions for all specimens to enable a subsequent standardization.

Figure 7. Damage Areas for Varied Impact Energies and Stacking Sequences

(a) Series 402

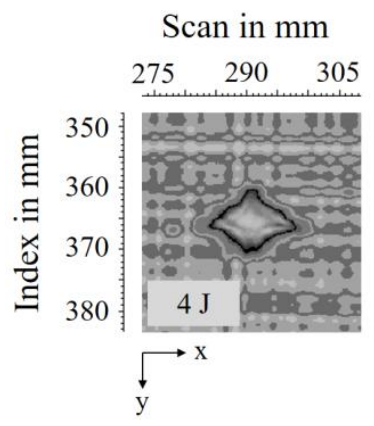

Scan in $\mathrm{mm} \quad$ Scan in $\mathrm{mm}$

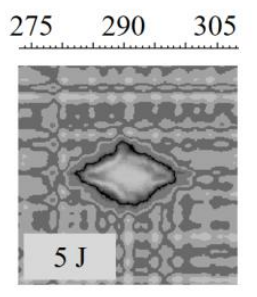

dB rel.
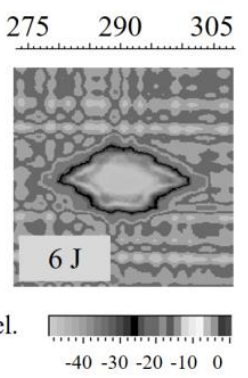

(b) Series 408

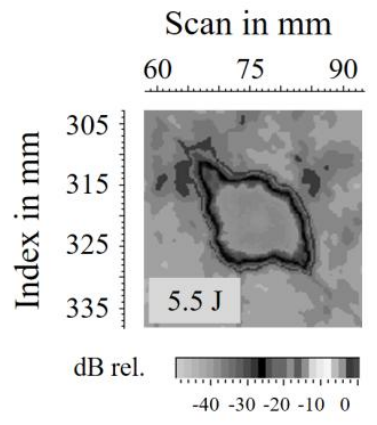


Furthermore, by comparing these damage shapes with Figure 8(b), it becomes apparent, that also the laminate stacking sequence has a major influence. The $\mathrm{C}$ scan images of Series 402 and Series 408 required small adjustment changes and are therefore not utterly similar. However, the different emphasis of the damage area alignment is clearly featured. As this alignment points in $0^{\circ}$-direction for Series 402 and even more distinctively in $-45^{\circ}$-direction for Series 408 , it is sensible to assume that the outermost laminate layers are primary responsible for the displayed shape of the impact area.

\section{Effect of Impact Damages}

In order to verify whether and to what extent impact damages influence the vibrational behavior, Plate 404-001 was closely surveyed in intact and damaged condition. The structural dynamic properties were calculated with the previously mentioned procedures. The obtained values for Mode 8 are graphically illustrated in Figure 8. The measurement points 9 and 10 were excluded from the analysis due to high scattering, most likely caused by measuring near node areas and the corresponding bad signal-to-noise ratio.

Figure 8. Effects of an Impact Damage in Plate 404-001

\section{(a) Damping Ratio}

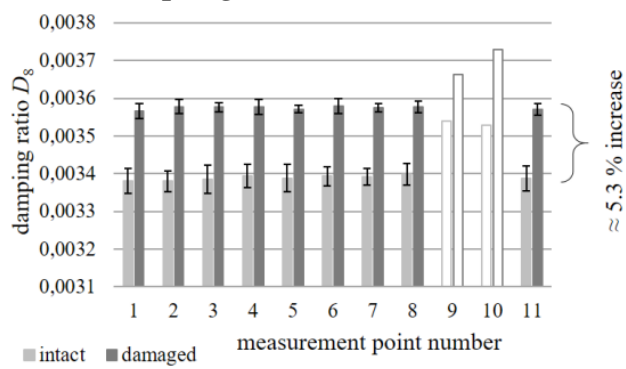

\section{(b) Loss Modulus}

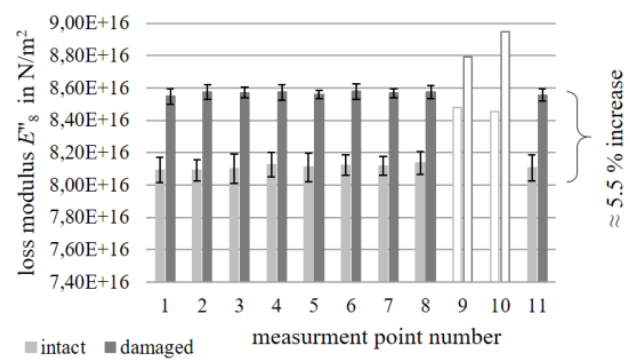

By comparison, Figure 8 clearly indicates increased damping ratio values for the plate in damaged condition. The damping ratio increased by approximately $5.3 \%$, while the loss modulus increased by $5.5 \%$ on average. During the test, environmental changes were minimal and are highly unlikely to cause such shifts. Another cause for this divergence may be suspected in influences associated to the specimen bearing. Hence, the measurement reproducibility was evaluated using probability plots and the measurement setup optimized (Kleppmann, 2013). As a consequence, it can be stated that the influence of the bearing is unaccountable for alterations of such extends. The remaining and previously assumed explanation is that the induced delamination areas extend the present material damping. This is probably caused by added friction surfaces. Using stronger excitation systems these new areas could even lead to crack edge rattling (Pfleiderer, 2006). In addition to the effects on the damping ratio and loss modulus, the eigenfrequencies and the storage modulus changed in a similar way. However, in percentage terms the shift was only about $0.07 \%$ for the eigenfrequency and $0.15 \%$ for the storage modulus, respectively. It is assumed that the mentioned bearing influences are responsible for this. 
In addition to Plate 404-001, two other specimens were measured and the increase in damping ratio calculated. Figure 9(a) displays the damping ratio of Mode 8 for intact plates in opposition to values gained from the plates in damaged condition. For all plates, the damping ratio increases significantly. The standard deviations are small and do not intersect for the plates in intact and damaged condition. Simultaneously, the need for normalization of the yielded damping ratios, or rather for structural dynamic properties in general, is apparent.

Figure 9. Effects of an Impact Damage in Series 404

(a) In comparison

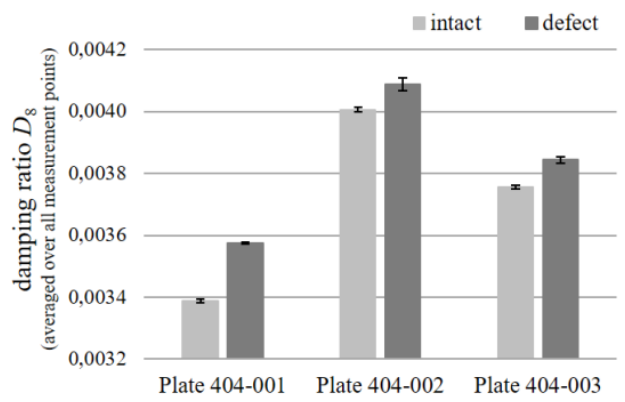

(b) Proportional increase

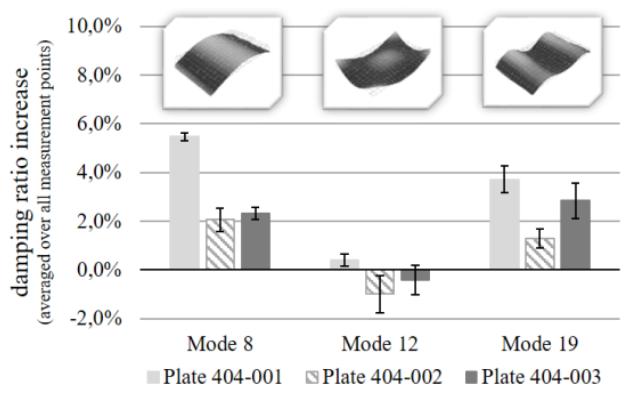

Figure 9(b) shows an extended evaluation of the impact damages' effect, since Mode 12 and Mode 19 are additionally viewed. Here, only proportional increases are plotted. For Mode 19, similar results to Mode 8 are gained, whereas Mode 12 indicates even small decreases of the damping ratio. Altogether, Mode 12 seems to display no significant alterations due to the fact that the standard deviations are intersecting, or almost intersecting the zero axis. Apparently, different eigenmodes exhibit a varying sensitivity to impact damages. The experimentally measured mode shapes of the mentioned eigenmodes are portrayed above the damping ratio increases in Figure 9(b). As apparent from these images, Mode 8 and 19 present flexural vibrations.

\section{Effect of Impact Damages}

To achieve a suitable normalization method, in particular for damping ratio values, different normalization values were picked and their effect compared. Thereby, the normalization approach by itself remains the same. As a first attempt, the damping ratios $D_{\mathrm{i}}$ of the three plates of Series 404 at measurement point 7 were normalized. The numbering and location of the measurement points is presented in Figure 6(a). The normalization itself was done by calculating the normalized damping ratio $D_{\text {i,norm }}$ with

$$
D_{\mathrm{i}, \text { norm }}=\frac{D_{\mathrm{i}}}{v^{m}} \text {. }
$$

The exponent $m$ determines how severe the normalization affects the damping ratios. The chosen normalization value $v$ is introduced hereafter. To obtain the subsequent line plots, $D_{\mathrm{i} \text {,norm }}$ was calculated varying the exponent $m$. Thereby, exponent $m$ was changed in the range from 0 , meaning no normalization 
was performed, to 20 with an increment of 0.1 . Further, the normalized mean damping ratio $\bar{D}_{\mathrm{i} \text {,norm }}$ is determined by

$$
\bar{D}_{\mathrm{i}, \text { norm }}=\frac{\sum D_{\mathrm{i}, \text { norm }}}{n},
$$

with the number of measurement values $n$ (Kleppmann, 2013). The new standard deviation $\sigma_{\mathrm{i} \text {,norm }}$ for the normalized values is calculated with

$$
\sigma_{\mathrm{i}, \text { norm }}=\sqrt{\frac{\sum\left(D_{\mathrm{i}, \text { norm }}-\bar{D}_{\mathrm{i}, \text { norm }}\right)}{n}} .
$$

Figure 10 displays plots for the normalization values plate mass, plate thickness, plate density and the product of the plate mass and plate thickness. The results for thickness, mass and the product of both are quite similar, as they all exhibit a possible minimum standard deviation value. The normalization by density otherwise only increases the standard deviations.

Figure 10. Standard Deviation of the Normalized Damping Ratios

(a) Thickness

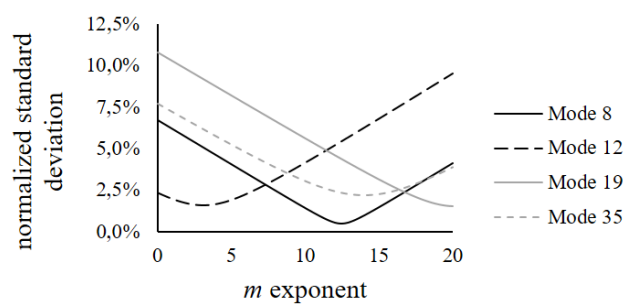

(c) Density

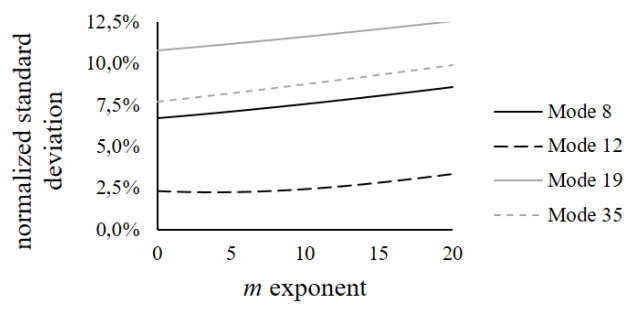

(b) Mass

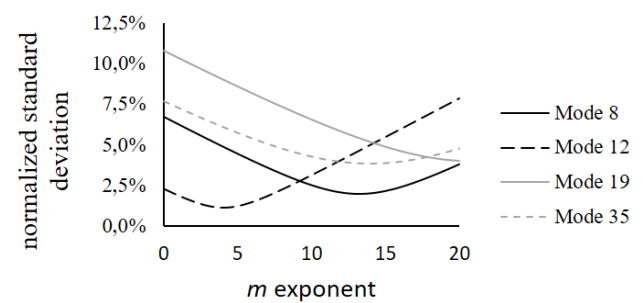

(d) Thickness $\times$ Mass

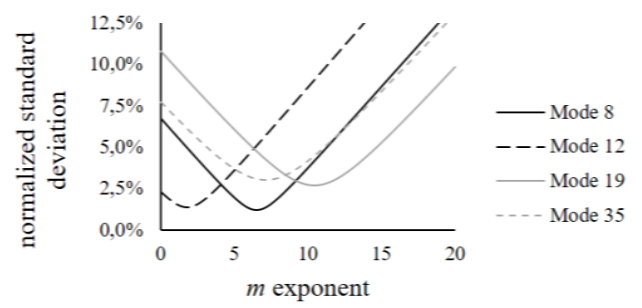

For the small sampling of three plates, a normalization by the product of mass and thickness seems to yield the best results. However, the different modes exhibit the minimum standard deviation at different $\mathrm{x}$-axis positions, thus indicating that an additional normalization by the mode number, the $k$-factor or eigenfrequency value could be sensible.

\section{Additional Influences on the Vibrational Behavior}

Apart from the investigated effect of impact damages other influences are assumed to affect the observed damping ratio values, alike. Hereby, influences of the measurement setup are probable but undesired. Besides the mentioned bearing influences, the excitation method may cause alterations. Therefore, studies concerning this issue were performed following a Design of Experiments (DOE) 
approach (Kleppmann, 2013). DOE studies are typically motivated by the obtained interdependencies. In this case, the loudspeaker output (A), the sweep speed (B) and the impact (C) influences were examined. The loudspeaker output can be regarded as an expression for the excitation strength. The DOE test points as well as the measured and averaged damping rations at these test points are displayed in Figure 11. The tested specimen was Plate 404-001 at Measurement Point 11.

Figure 11. Design of Experiments with the Outcome Variable Damping Ratio

(a) DOE Test Points

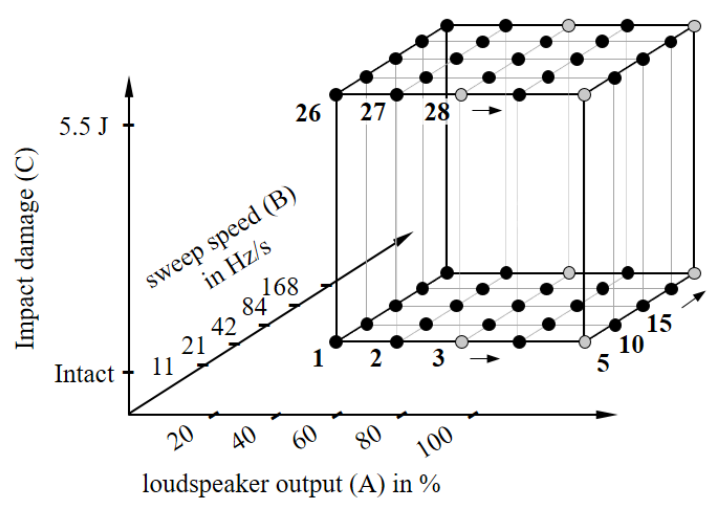

(b) Area Plots

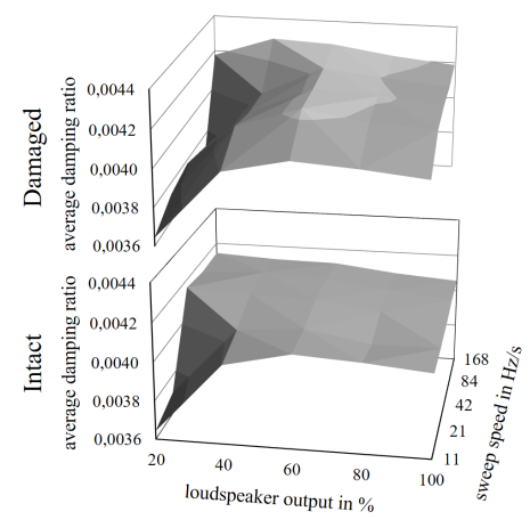

Comparing the two area plots in Figure 11(b), an overall increase of the damping ratio is apparent for the damaged plate. Further, for low loudspeaker outputs of $20 \%$ and $40 \%$, the damping ratios deviate considerably, leading to the observable bend in the area plot. An additional result is that the scattering for such adjustment is high, thus measurements with little excitation energy should be avoided. Based on this preceding analysis, eight measurement points were singled out for continuingly examination. These DOE test points, marked in Figure 11(a), were used as the basis for a $2^{3}$ Factorial Design (Kleppmann, 2013). The results for the influence of different variables on the outcome variable damping ratio and the interdependencies are graphically and numerically shown in Figure 12.

Of all three variables, the impact (C) appears to represent the most influential parameter, as it increased the damping ratio by $3.2 \%$ in this DOE analysis. Figure 12 further shows that the loudspeaker output (A) and the sweep speed (B) also affect the damping ratio, although, compared to the impact, the alterations are smaller. Hence, for performing structural dynamic measurements, the adjustments of the acoustic excitation should remain consistent or require normalization. Strong interdependencies between the variables were not found. Based on this, it can be stated that in the surveyed DOE area, neither a certain sweep speed nor a particular loudspeaker output improves the impact damage detection. Thus, damage detection is equally feasible by examining the specimens with a fast changing excitation frequency. 
Figure 3. Results of the $2^{3}$ DOE Analysis

major influences

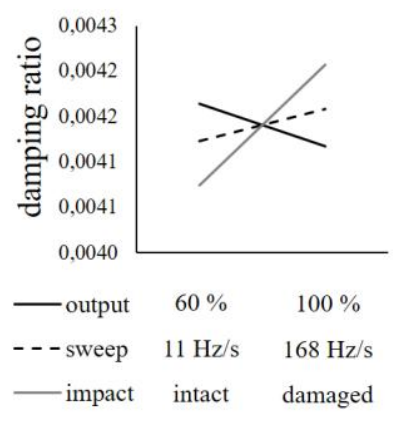

influences:

A: loutspeaker output

B: sweep speed

C: impact damage

AB: output $x$ sweep

AC: output $x$ impact

BC: sweep $\times$ impact

$$
\begin{aligned}
& \mathrm{A}=-4.7 \mathrm{E}-5(\approx-1.5 \%) \\
& \mathrm{B}=3.6 \mathrm{E}-5(\approx 0.9 \%) \\
& \mathrm{C}=13.4 \mathrm{E}-5(\approx 3.2 \%) \\
& \mathrm{AB}=-2.6 \mathrm{E}-5(\approx-0.6 \%) \\
& \mathrm{AC}=0.6 \mathrm{E}-5(\approx 0.1 \%) \\
& \mathrm{BC}=0.7 \mathrm{E}-5(\approx 0.2 \%)
\end{aligned}
$$

interdependencies

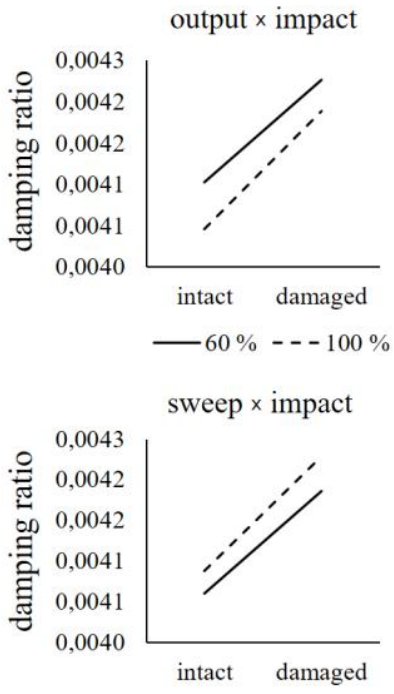

$-11 \mathrm{~Hz} / \mathrm{s}---168 \mathrm{~Hz} / \mathrm{s}$

\section{Conclusions and Outlook}

Damages or rather delamination areas increase with the impact energy. An impact damage causes different delamination shapes depending on the laminate stacking. Thereby, the damage shape shows an emphasis in the outermost layers' direction. In regards to the setup, excitation strength and frequency sweep speed were identified to influence the measured damping ratios. Hence, it is sensible to include both influences in normalization approaches. For the surveyed setup adjustments, only minor inter-dependencies between changes in the acoustic excitation and the impact damage's effect were found. Whether substantially greater excitation strengths improve the damage detection is still pending. The normalization of the different plate-shaped specimens proves rather difficult, thus statements concerning the material integrity are only completely reliable, if vibrational characteristics prior to the impact damage are available. Comparing the structural dynamic properties of plates in intact condition and with a BVID yields the result that the damping and loss modulus in particular, increase significantly with an impact damage. Consequently, the impact damage appears to be in direct correlation to the material damping. In summary, by taking various influences into account, material integrity statements based on the damping ratio of FRP plates represents a promising approach.

\section{Acknowledgments}

This paper originates from the involvement in the research project 'Lebensdauerüberwachung von faserverstärkten Kunststoffen auf Basis der 
strukturdynamischen Werkstoffdämpfung - DampSIM ${ }^{1}$ funded by the Bavarian Research Foundation and was conducted at the OTH Regensburg in the Laboratory for Composite Technology directed by Prof. Dr.-Ing. Ingo Ehrlich.

\section{References}

DIN 65561 (1991). Aerospace - Fibre reinforced plastics - Testing of multi-directional laminates - Determination of compressive strength after impact test. Standards committee 'Luftfahrt' (NL) in DIN German Institute for Standardization, Beuth Verlag, Berlin.

DIN EN ISO 1172 (1998). Textile-glass-reinforced plastics - Prepregs, moulding compounds and laminates - Determination of the textile-glass and mineral-filler content. Standards committee 'Kunststoffe' (FNK) in DIN German Institute for Standardization/Standards committe 'Luftfahrt' (NL) in DIN, Beuth Verlag, Berlin.

DIN EN ISO 6721-1 (2011). Plastics - Determination of dynamic mechanical properties Part 1: General principles. Standards committee 'Kunststoffe' (FNK) in DIN German Institute for Standardization/Standards committee 'Materialprüfung' (NMP) in DIN, Beuth Verlag, Berlin.

DIN EN ISO 6721-3 (1996). Plastics - Determination of dynamic mechanical properties Part 3: Flexural vibration; resonance-curve. Standards committee 'Kunststoffe' (FNK) in DIN German Institute for Standardization/Standards committee 'Materialprüfung' (NMP) in DIN, Beuth Verlag, Berlin.

Dresig, H. and Holzweißig, F. (2010). Dynamics of Machinery. Theory and Applications. Springer-Verlag, Berlin, Heidelberg. DOI=http://dx.doi.org/10.1007/978-3-540-89940-2.

Ehrlich, I. (2004). Impactverhalten schwach gekrümmter FVK-Strukturen. [Impact behavior of slightly curved FRP structures.] Doctoral Thesis. Universität der Bundeswehr, München. URL=http://athene-forschung.unibw.de/doc/85244/852 44.pdf.

Ehrlich, I., Dinnebier, B. and Jost, C. (2015). Comparison of Impact Delaminations in CFRP using Ultrasonic Testing, Microfocus Computed X-Ray Tomography and Micrographic Cross-Sections. Journal of Achievements in Materials and Manufacturing Engineering. Vol. 73, Issue 2, pp. 128-138, International OCSCO World Press. URL=http://www.jour nalamme.org/vol73_2/73212.pdf.

Ewins, D. J. (2000a). Modal Testing - Theory, Practice and Application. Research Studies Press Ltd., Hertfordshire. ISBN=978-0863802188.

Ewins, D. J. (2000b). Basics and state-of-the-art of modal testing. Sādhanā, Vol. 25, Part 3, pp. 207-220, Indian Academy of Sciences, Bangalore. DOI= http://dx.doi.org/ 10.1007/BF02703540.

Gibson, R. F. (2000). Modal Vibration Response Measurements for Characterization of Composite Materials and Structures. Composites Science and Technology. Vol. 60, pp. 2769-2780, Elsevier Science Ltd, Amsterdam. DOI=http://dx.doi.org/10.1016/ S0266-3538(00)00092-0.

Gibson, R. F. (2012). Principles of composite material mechanics. CRC Presss, New York. ISBN=978-1439850053.

Gross, D., Hauger, W. and Wriggers, P. F. (2011). Technische Mechanik 4. Hydromechanik, Elemente der Höheren Mechanik, Numerische Methoden. [Engineering mechanics 4.

\footnotetext{
${ }^{1}$ engl.: 'Lifetime monitoring of fiber-reinforced plastics based on the structural dynamic material damping - DampSIM'.
} 
Hydromechanics, elements of higher mechanics, numerical methods.] Springer-Verlag, Berlin, Heidelberg. DOI=http://dx.doi.org/ 10.1007/978-3-642-16828-4.

Kleppmann, W. (2013). Taschenbuch Versuchsplanung. Produkte und Prozesse optimieren. [Paperback experimental design. Optimization of products and processes.] Carl Hanser Verlag, München, Wien. DOI=http://dx.doi.org/10. 3139/9783446429420.

Morlo H. and Kunz J. (1990) Impact Behaviour of Loaded Composites. Developments in the Science and Technology of Composite Materials, pp. 987-991, Springer Netherlands, Dordrecht. DOI=http://dx.doi.org/10.1007/978-94-009-0787-4_142.

Pfeiderer, K. (2006). Frequenzkonversion aufgrund nichtlinearer akustischer Phänomene. Grundlagen und Anwendung zu defektselektiven zerstörungsfreien Prüfung. [Frequency conversion due to non-linear acoustic phenomena. Fundamentals and application of damage exclusive, non-destructive testing.] Doctoral Thesis. Universität Stuttgart, Stuttgart. DOI= http://dx.doi.org/10.18419/opus-1707.

Schoßig, M. (2011). Schädigungsmechanismen in faserverstärkten Kunststoffen. Quasistatische und dynamische Untersuchungen. [Damage mechanism in fiberreinforced plastics. Quasistatic and dynamic analysis.] Vieweg+Teubner, Wiesbaden. DOI=http://dx.doi.org/10.1007/978-3-8348-9924-8.

Schürmann, H. (2007). Konstruieren mit Faser-Kunststoff-Verbunden. [Construction with fiber-platic composites.] Springer-Verlag, Berlin, Heidelberg. DOI=http://dx.doi.org /10.1007/978-3-540-72190-1.

Wu, J. and Moslehy, F. A. (1995) On modal testing using speaker excitation. 13th International Modal Analysis Conference (1995 IMAC XIII). SEM Society for Experimental Mechanics, Bethel. URL=https://www.sem.org/Proceedings/Conferen cePapers-Paper.cfm?ConfPapersPaperID=40250. 
